\title{
obituary
}

\section{Dr Nekhant (Raj) Rathod}

\section{Formerly Consultant} Psychiatrist, Cuckfield and Crawley Health District, and Consultant to WHO

Raj Rathod was born on 1 July 1919 and grew up in Poona, India. He first studied medicine at the BJ medical school in Poona and qualified in 1940 as a licentiate of the College of Physicians and Surgeons (LCPS). At this stage of his life financial support was difficult and the training for the LCPS was shorter. In 1946 he obtained a 2-year scholarship at the Grant Medical College in Bombay and did research on liver function tests in patients with chronic diarrhoea. He also obtained his MB, BS in 1948 at Bombay University. His research work stimulated an interest in the psychological problems of his patients and to better his understanding he attended a psychotherapy clinic. This interest in psychological medicine developed and it was suggested he should come to the UK and train in psychiatry at the Maudsley Hospital.

With generous financial help from colleagues and friends, he came to England in 1953 and took up a post at the Maudsley as an unpaid clinical assistant. He realised that in order to continue his training he had to obtain a paid job, the alternative being to return to India. After a sympathetic discussion with the Dean, Dr D. L. Davies, he was advised to apply for a registrar post and was successful in obtaining one. He went on to complete his training at the Maudsley and Bethlem Royal Hospitals. During this time he also studied for the MRCP. He was granted the MRCPsych in 1971 and was elected FRCPsych in 1973.

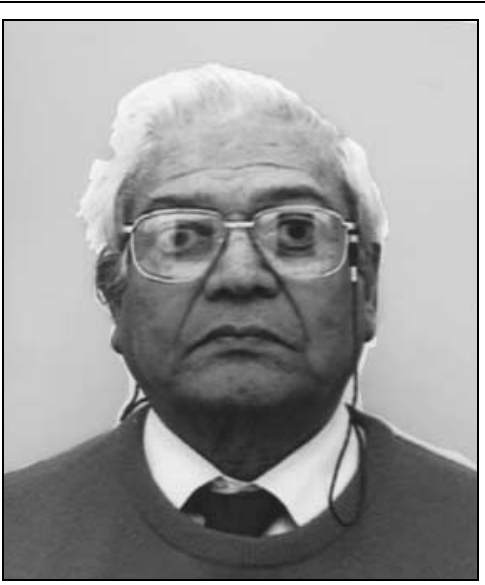

From 1958 to 1964 he was in charge of the unit for alcoholism at Warlingham Park Hospital. This was the beginning of a lifelong interest in the problems of dependency and addiction to alcohol and drugs, resulting in his first published paper.

In 1964 he was appointed as a consultant at Graylingwell Hospital in Chichester and became responsible for the establishment of St Christopher's Day Hospital in Horsham (one of the earliest psychiatric day hospitals). Following a reorganisation in 1968, he was based in Horsham and Crawley and put on the staff of Roffey Park and, later, Horsham and Crawley hospitals.

At an interview with a patient on remand in Brixton prison in 1966 he discovered the existence of a group of heroin injectors in the town of Crawley, the first time such a group had been identified outside London. This group was closely studied by Dr Rathod (initially with Drs Richard de Alarcon and lan Thompson). The studies suggested that the pattern of misuse was copied by one person to another on the basis of friendship and social contact, a process which Raj likened to contagion. These patients were offered treatment in the form of psychotherapy and support on an out-patient basis. They were not offered narcotic-substitution treatment, which he strongly believed to be wrong and illogical.

He maintained an interest in this group and followed them up for a total of 33 years. Indeed, the longitudinal picture of what happened to these patients was the focus of his research, as well as the sort of personality and mental health problems evident in their childhood before the onset of drug misuse.

He published numerous papers, not only relating to this group, on issues in the field of addiction and substance misuse.

The World Health Organization (WHO) appointed him to represent the UK on a special study group in Geneva in 1970 and 1971 and he also undertook a visit to India to report to the WHO on the matter of research into the use of cannabis in India. In later years he made numerous trips to various African countries through the International Council on Alcohol and Addictions (ICAA) to give advice on the training of professional and voluntary groups. From 1972 to 1979 he was secretary of the Society for the Study of Addiction.

His appetite for work in his chosen field was insatiable and his enthusiasm inspired others. He was also a medical member of the Mental Health Review Tribunal for several years. He continued his writing until the last few weeks of his life, including a book he co-authored with Mary Addenbrooke entitled Recovering from Addiction, which is awaiting publication.

He died on 5 June 2007.

Anthony Parker

doi: 10.1192/pb.bp.107.018622 